\title{
Distinct roles of NK cells in viral immunity during different phases of acute Friend retrovirus infection
}

\author{
Elisabeth Littwitz, Sandra Francois, Ulf Dittmer and Kathrin Gibbert ${ }^{*}$
}

\begin{abstract}
Background: In many virus infections natural killer (NK) cells are critical for the rapid containment of virus replication. Polymorphisms in NK cell receptors as well as viral escape from NK cell responses are associated with pathogenesis and viral loads in HIV-infected individuals, emphasizing their importance in retroviral immunity. In contrast, NK cells of LCMV-infected mice dampened virus-specific T cell responses resulting in impaired virus control. Thus, the exact role of NK cells during different phases of viral infections remains elusive. In this study we characterized the NK cell response at different time points of an acute retroviral infection by using the Friend retrovirus (FV) mouse model.

Findings: Depletion of NK1.1 $1^{+}$cells during the initial phase of FV infection (3 to 4 days post infection) resulted in increased viral loads, which correlated with enhanced target cell killing and elevated NK cell effector functions. At days 7 to 15 post infection, NK and NKT cells did not contribute to anti-retroviral immunity. In the transition phase between acute and chronic infection (30 days post infection), NK and NKT cells exhibited an inhibitory role and their depletion resulted in reduced viral loads and significantly improved FV-specific $C D 8^{+} T$ cell responses.

Conclusions: Our results demonstrate an opposed activity of NK cells during retroviral infection. They were protective in the initial phase of infection, when adaptive $T$ cell responses were not yet detectable, but were dispensable for viral immunity after $\mathrm{T}$ cell expansion. At later time points they exhibited regulatory functions in inhibiting virus-specific CD $8^{+}$ T cell responses.
\end{abstract}

Keywords: NK cells, Friend retrovirus, Effector T cells, Regulatory function, Viral control

\section{Findings}

NK cells are cytotoxic cells of the innate immune system, which contribute to the control of many virus infections. They express a variety of different receptors on their surface driving their functions towards activating or inhibitory responses. NK cells mediate their effector functions through recognition and elimination of virus-infected cells. However, for several viral infections it was shown that NK cells suppress the adaptive immunity by killing virus-specific $\mathrm{T}$ cells [1-4]. This resulted in increased viral loads and might contribute to impaired viral clearance. On the other hand it has been demonstrated that HIV uses different mechanisms to escape NK cell responses. HIV modulates the ligand expression of the activating NK cell receptor NKG2D on infected cells resulting in reduced NK cell activation [5]. Additionally, mutational adaptation of HIV has been shown to result in stimulation of inhibitory receptors on NK cells and subsequent escape from NK cell-mediated immune pressure [6]. These opposed mechanisms suggest that NK cells may have distinct effects in different phases of viral infections. Here we analyzed these effects in the murine Friend retrovirus (FV) model by depletion of NK cells at different time points after retroviral infection. The antiviral role of NK cells during an acute FV infection has been investigated in several previous studies. However, almost all of these studies were performed with FV stocks containing Lactate dehydrogenase elevating virus (LDV). Only one recent paper with LDV-free FV showed that NK cells recognize infected target cells by interaction of RAE-1 and NKG2D [7]. LDV induces a massive type I interferon response during acute infection, which we have shown to significantly modulate NK cell responses [8]. Since LDV-free FV induces only barely detectable levels of type I interferons, the previous

\footnotetext{
* Correspondence: Kathrin.gibbert@uni-due.de

Institute for Virology of the University Hospital in Essen, University of Duisburg-Essen, Essen, Germany
} 

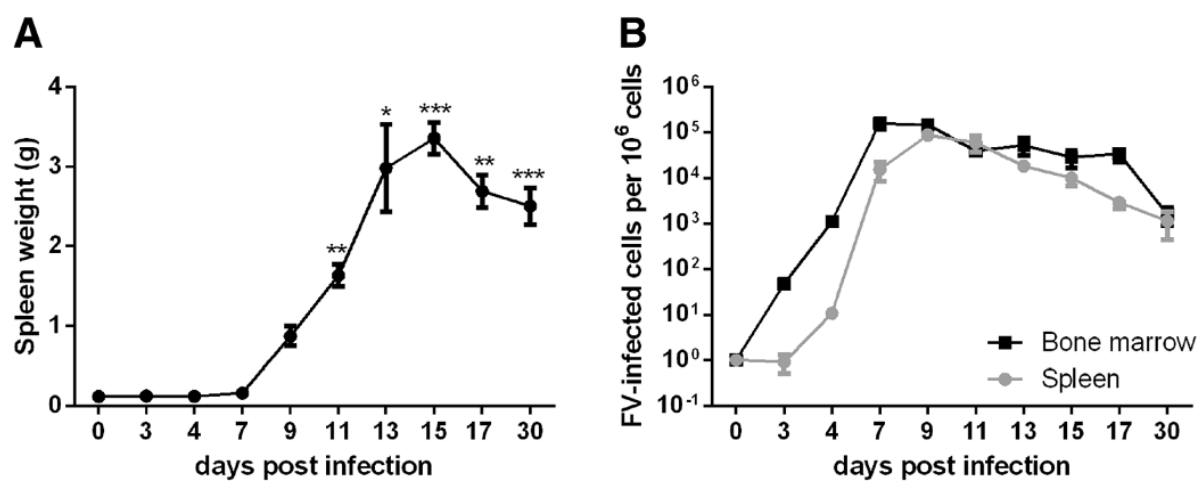

Figure 1 Kinetics of FV infection. Spleen weights of FV-infected CB6F1 mice were determined at different time points after FV infection (A). Statistically significant differences compared to naive mice $(0 \mathrm{dpi})$ are indicated by * for $p<0.05$; ** for $p<0.01$; *** for $p<0.001$. Viral loads of FV-infected CB6F1 mice were analyzed in bone marrow and spleen using an infectious center assay (B). At least six mice per group were analyzed and the mean values for each group are indicated by a symbol + SEM.

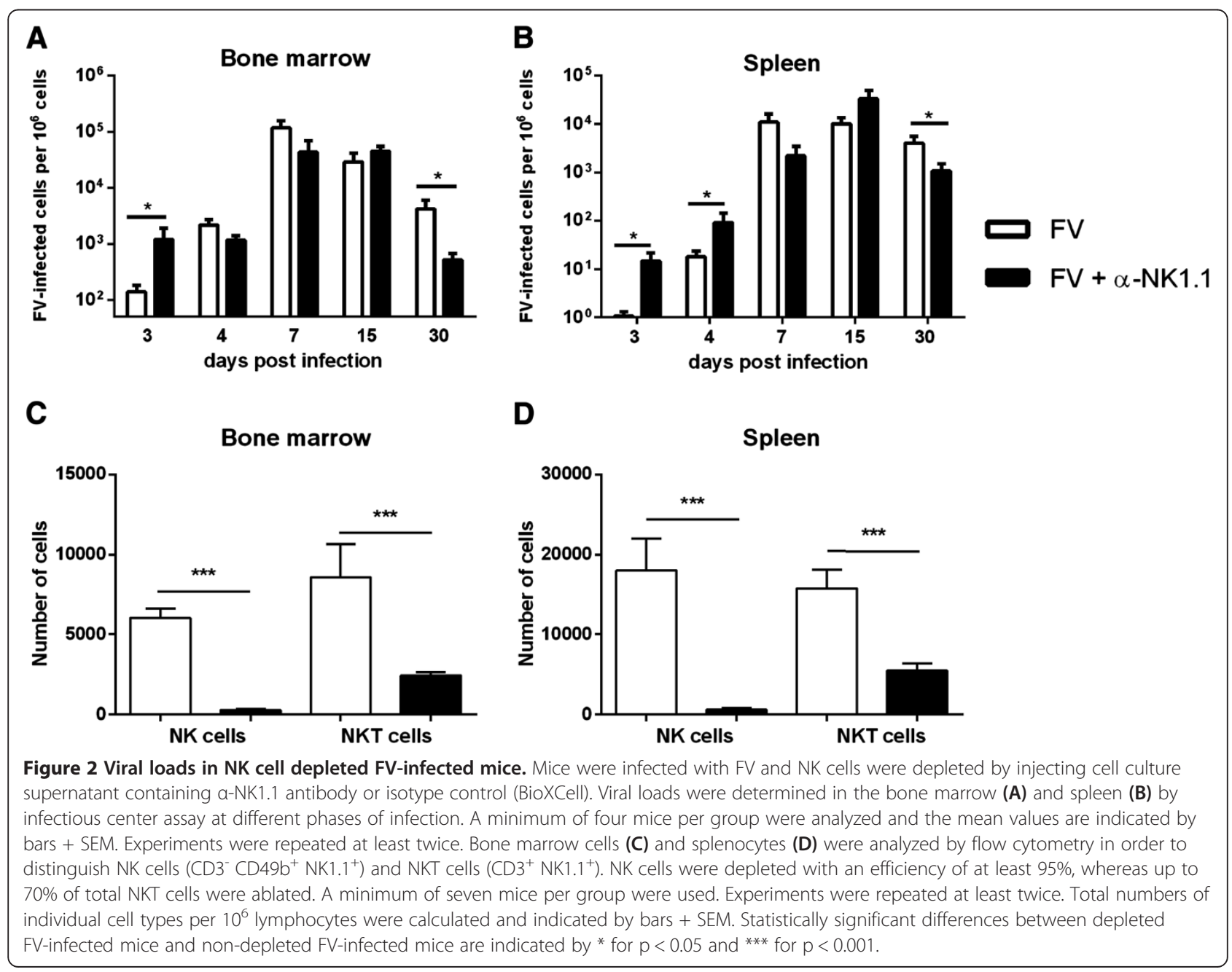




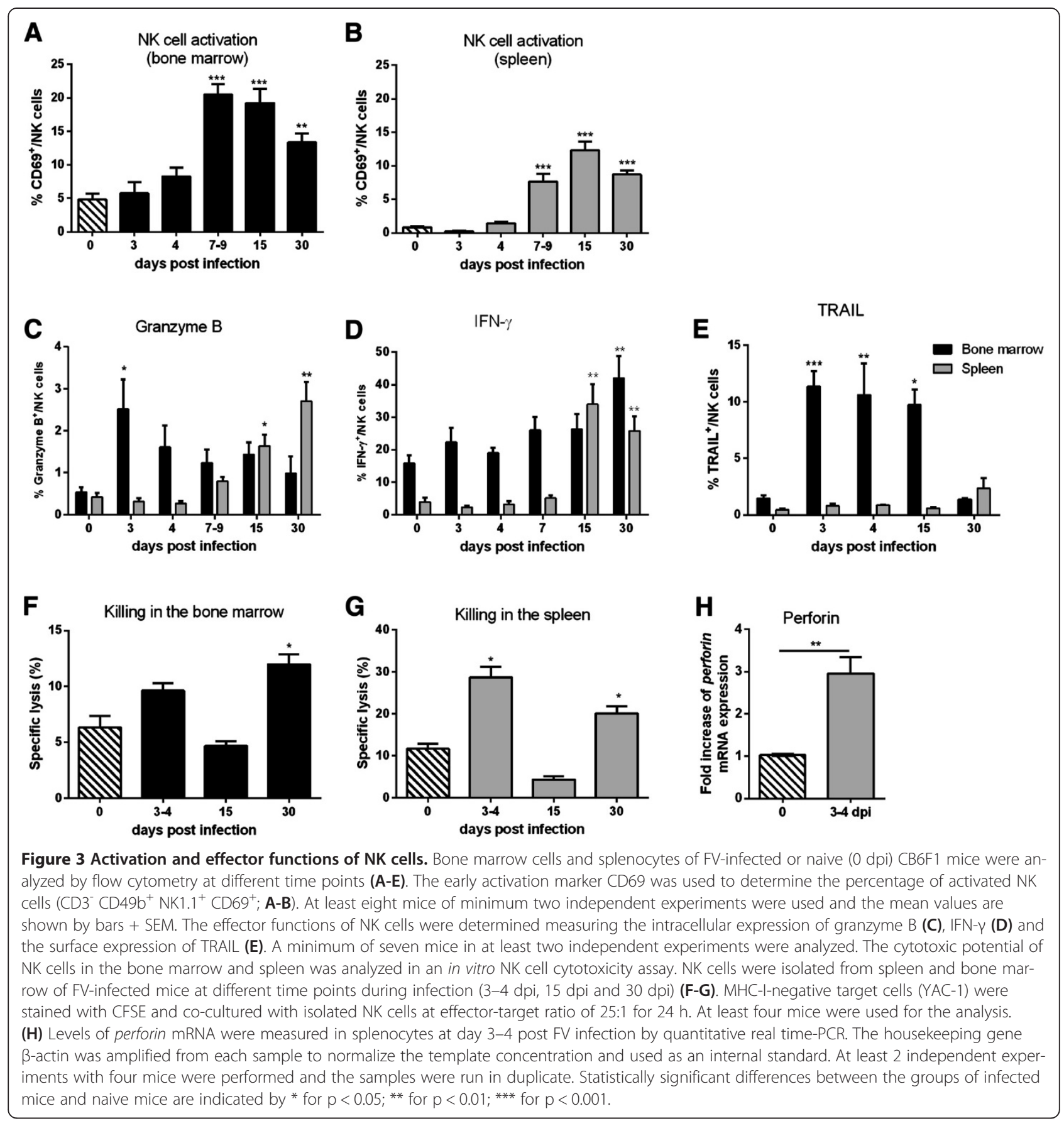

studies provide very little useful information on the role of NK cells in the immune control of FV infection. We therefore addressed this question in mice that were infected with a LDV-free FV stock.

\section{Kinetics of FV infection in different lymphoid organs}

To characterize the effector functions of NK cells during different phases of FV infection, we first analyzed the kinetics of virus infection in CB6F1 mice, a cross of highly susceptible Balb/c mice and resistant C57BL/6 mice. FV infection resulted in the development of a severe splenomegaly starting at day 9 post infection (dpi) demonstrating their FV susceptibility (Figure 1A). Spleen weights peaked $15 \mathrm{dpi}$ with a significant higher mean weight ( $3.36 \mathrm{~g}$ ) compared to naive control mice $(0.12 \mathrm{~g})$ and afterwards steadily declined. The kinetics of acute viral loads in spleen and bone marrow of infected mice are shown in Figure 1B. These organs were known to be the main reservoir for FV replication [9]. During initial FV infection, virus-infected 


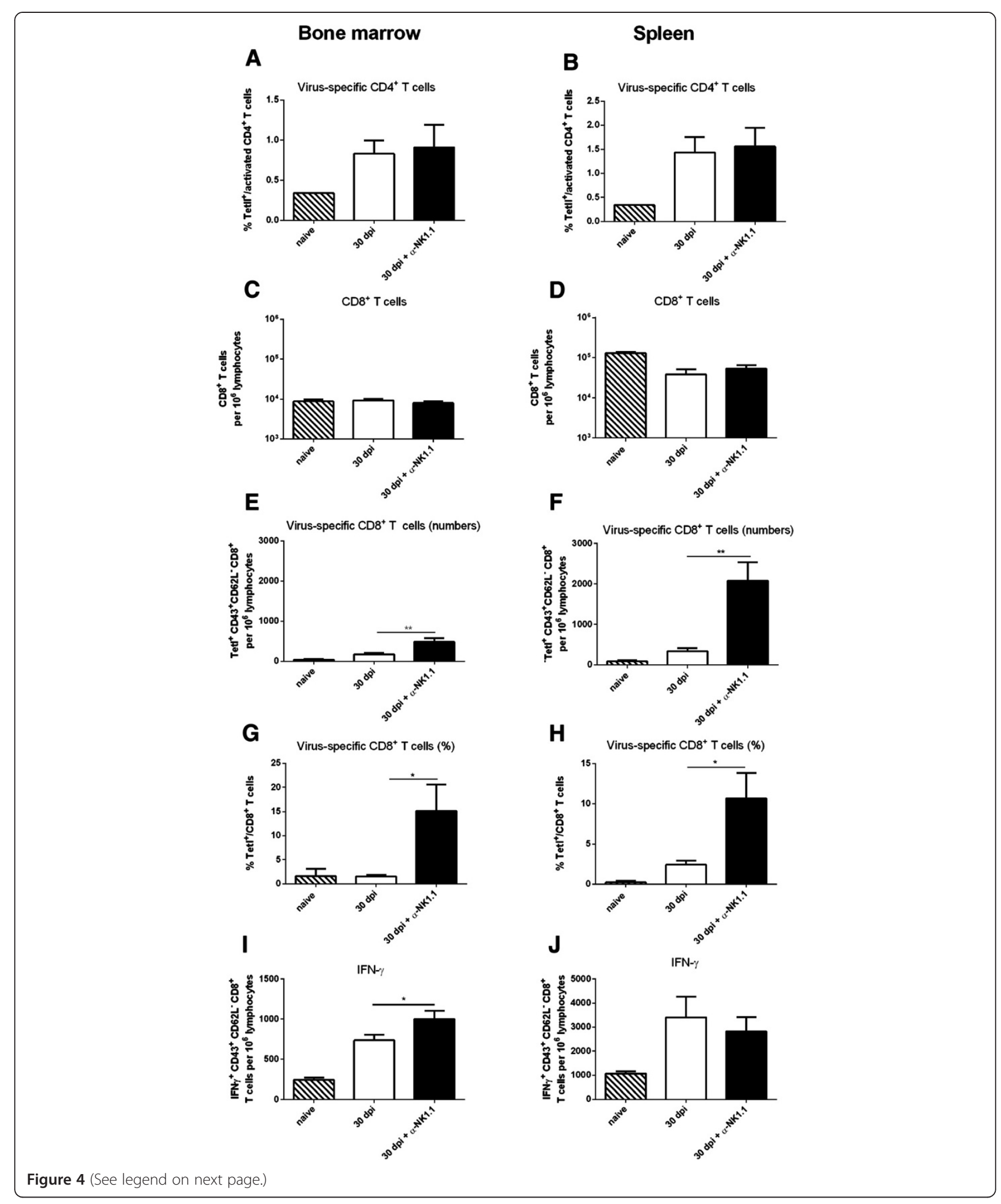


(See figure on previous page.)

Figure $4 \mathrm{FV}$-specific $\mathrm{CD}^{+}$and $\mathrm{CD} 8^{+} \mathrm{T}$ cell responses in the absence of NK cells. CB6F1 mice were infected with $\mathrm{FV}$ and one group of mice was NK cell depleted. Bone marrow and spleen cells were analyzed at $30 \mathrm{dpi}$. For the analysis of activated $\left(\mathrm{CD} 43^{+} \mathrm{CD} 44^{+}\right)$virus-specific $\mathrm{CD} 4^{+} \mathrm{T}$ cells, bone marrow (A) and splenic (B) cells were stained with MHC class II-antibody tetramers specific for F-MuLV env fn20 [11]. Numbers of total $\mathrm{CD}^{+} \mathrm{T}$ cells were analyzed by flow cytometry in bone marrow $(\mathbf{C})$ and spleen $(\mathbf{D})$. Numbers $(\mathbf{E}, \mathbf{F})$ and percentages $(\mathbf{G}, \mathbf{H})$ of activated $\left(\mathrm{CD} 43^{+}\right.$ $\mathrm{CD} \mathrm{L}^{-}$) effector $\mathrm{CD} 8^{+} \mathrm{T}$ cells, which are specific for the FV gag $\mathrm{L}$ epitope, were stained for $\mathrm{D}^{\mathrm{b}}$ gag $\mathrm{L}$ class I tetramers and determined by flow $\mathrm{Cy}-$ tometry in bone marrow $(\mathbf{E}, \mathbf{G})$ and spleen $(\mathbf{F}, \mathbf{H})$. Bone marrow $(\mathbf{I})$ and splenic $(\mathbf{J})$ activated $C D 8^{+} \mathrm{T}$ cells were stained intracellularly for IFN- $\gamma$. A minimum of seven mice were used for analysis. At least two independent experiments were performed. Significant differences between the groups were analyzed by using the unpaired Students $t$ test (** for $p<0.01$ ) statistically significant by an unpaired t test (** for $p<0.01$ ).

cells were detected as early as $3 \mathrm{dpi}$ in the bone marrow and 4 dpi in the spleen, the viral loads peaked 7 and $9 \mathrm{dpi}$, respectively. Subsequently, the viral loads constantly declined until $30 \mathrm{dpi}$.

To analyze the impact of NK cells on FV replication, we depleted NK cells during different phases of infection. Here, we focused on three different time points of acute FV infection. 1) The initial phase (3-4 dpi), when only NK cells are able to kill virus-infected cells because $\mathrm{T}$ cell responses are not yet developed [9]. 2) At the peak of virus replication (7-15 dpi), when virus-specific $\mathrm{T}$ cells are detectable and eliminate infected target cells [9]. 3) The late phase (30 dpi), when viral loads are reduced but FVinduced leukemia starts to develop. Then cytotoxic $\mathrm{CD} 8^{+}$ $\mathrm{T}$ cells become dysfunctional in FV infection [9].

\section{Anti-retroviral effects of NK cells during initial FV infection}

As in vivo depletion with antibodies against NK1.1 has the potential to affect other cell subsets, we analyzed their influence on NKT cells. Figure 2C and 2D illustrate an up to $70 \%$ depletion of NKT cells by application of $\alpha$-NK1.1 in spleen and bone marrow of FV-infected mice. Thus, both cell subsets, NK and NKT cells, might influence antiretroviral immunity. Figure $2 \mathrm{~A}$ and $2 \mathrm{~B}$ indicate that ablation of NK and NKT cells in the initial phase of FV infection (3-4 dpi) resulted in a significant increase in viral loads compared to non-depleted control mice, which was determined by infectious center (IC) assay (for detailed description of experimental procedures, see Additional file 1) and RT-PCR analysis (data not shown). In the bone marrow (Figure 2A) an 8.5-fold increase in viral loads was observed at 3 dpi. In the spleen (Figure 2B) 5 -fold to 15 -fold elevated viral loads were detected at 4 and $3 \mathrm{dpi}$, respectively. At this early time point of infection no significant activation of NK and NKT cells, indicated by the expression of CD69, was found (Figure 3A, 3B and data not shown). However, functional activation of NK cells, but not NKT cells (data not shown), were observed, reflected by a significant increase in tumor necrosis factor related apoptosis inducing ligand (TRAIL) and granzyme B expression (Figure $3 \mathrm{C}$ and $\mathrm{3E}$ ) in the bone marrow of FV-infected mice. In splenic NK cells increased levels of perforin mRNA were detected at $4 \mathrm{dpi}$ (Figure $3 \mathrm{H}$ ) compared to naive controls. The effector function of NK cells during the initial infection was confirmed in an in vitro cytotoxicity assay. Increased killing of target cells (YAC-1) was mediated by NK cells from spleen or bone marrow of FVinfected mice (Figure 3F and 3G). Altogether, during the initial phase of $\mathrm{FV}$ infection, when $\mathrm{T}$ cell responses are not yet developed, NK cells or NKT cells mediate early protective anti-retroviral immunity.

\section{No effect of NK cells during the peak FV replication}

Next, we examined the function of NK cells 7-15 dpi, when $\mathrm{T}$ cells expand and control FV replication $[9,10]$. Depletion of NK and NKT cells during this phase of infection did not influence viral loads in both investigated organs, which was shown by an IC assay (Figure 2A-2B) and RT-PCR analysis (data not shown). However, at that time point both cell subsets started to express high levels of CD69 (Figure 3A, 3B and data not shown). The expression of the functional molecules granzyme $B$, interferon- $\gamma$ (IFN), or TRAIL were elevated only in NK cells from spleen or bone marrow (Figure 3C-3E), but isolated NK cells failed to eliminate target cells (Figure 3F and 3G) which correlated with the findings from the depletion experiments (Figure 2A-2B). Thus at 7 to 15 dpi NK cells and NKT cells did not contribute to antiviral immunity, which is mainly mediated by $\mathrm{CD} 8^{+} \mathrm{T}$ cells during peak viral replication [9].

\section{Negative effects of NK cells during the late phase of acute FV infection}

During the late phase of FV infection (30 dpi) susceptible mice start to develop a lethal erythroleukemia. Then virus-infected as well as transformed cells are potential targets for NK cells. To evaluate their role during this phase, we performed depletion experiments starting at 20 dpi. Surprisingly, application of $\alpha$-NK1.1 antibody resulted in a significant reduction of viral loads at $30 \mathrm{dpi}$, which was observed by an IC assay (Figure 2A-2B) and RT-PCR analysis (data not shown). An 8-fold decrease of the viral loads in the bone marrow (Figure 2A) and a 4-fold reduction in the spleen (Figure 2B) was observed compared to control mice. NK cells were still activated $\left(\mathrm{CD}^{+} 9^{+}\right)$at this late time point (Figure 3A and $3 \mathrm{~B}$ ) and expressed elevated levels of granzyme B (Figure 3C) and IFN- $\gamma$ (Figure 3D). TRAIL was not detected on NK cells from mice infected 
for 30 days (Figure 3E). Next, we analyzed if up-regulation of effector molecules correlated with the cytotoxic potential of NK cells during late acute FV infection. Figure 3F and 3 G show that NK cells isolated 30 dpi significantly lysed target cells. 30 dpi NK cells were activated and had an effector phenotype, which allowed them to specifically kill target cells in vitro. Surprisingly, NK and NKT cells did not contribute to viral immunity but rather negatively influenced viral loads during the late phase of acute FV infection.

\section{NK cell depletion improved specific $\mathrm{CD}^{+} \mathrm{T}$ cell responses in FV-infected mice}

The depletion experiments revealed that the presence of NK or NKT cells during the late phase of acute FV infection enhanced viral loads. We addressed the question, if these cells impair virus-specific $\mathrm{T}$ cell responses. Therefore, mice with or without NK cells and NKT cells were analyzed for their virus-specific $\mathrm{T}$ cell responses $30 \mathrm{dpi}$. Depletion with $\alpha$-NK1.1 antibody had no significant effect on the percentages of virus-specific $\mathrm{CD}_{4}^{+} \mathrm{T}$ cells (Figure $4 \mathrm{~A}$ and $4 \mathrm{~B})$. Whereas the depletion significantly increased the frequency and numbers of virus-specific $\mathrm{CD} 8^{+} \mathrm{T}$ cells in both investigated organs without changing the total numbers of $\mathrm{CD}^{+} \mathrm{T}$ cells (Figure $4 \mathrm{C}-4 \mathrm{H}$ ). Further analysis of the functionality of effector $\mathrm{CD} 8^{+} \mathrm{T}$ cells revealed a significant higher amount of $\mathrm{CD}^{+} \mathrm{T}$ cells producing IFN- $\gamma$ in the bone marrow of depleted mice (Figure 4I). These data imply that activated NK cells suppress $\mathrm{CD}^{+} \mathrm{T}$ cell responses and impair anti-retroviral immunity during the late phase of acute FV infection.

In this report, we analyzed NK cell effector functions and their impact on viral replication and adaptive immune responses during acute retroviral infection. Altogether, we identified an antiviral role of NK cells or NKT cells during the initial FV infection (3-4 dpi), which might contribute to the early control of viral replication. Others could already show that mice deficient in NKT cells were more susceptible in controlling some viruses like HSV-1/2, MCMV, and EMCV (reviewed in [12]). Thus, either NK cells or NKT cells might participate in the early antiviral immunity against FV. Later during infection, $\mathrm{CD}^{+} \mathrm{T}$ cells become the key players of anti-retroviral immunity [9] and replace NK and NKT cell responses. However, the strong $\mathrm{CD}^{+} \mathrm{T}$ cell responses might have to be counterregulated in some virus infections to prevent immunopathology. There is growing evidence that NK cells and not NKT cells play a role in this regulation. In the LCMVmodel, it was shown that depletion of NK cells alone enhanced $\mathrm{T}$ cell responses and thus mice could control viral replication and thereby prevent chronic infection [2]. The NK cell-mediated inhibition of $\mathrm{CD}^{+} \mathrm{T}$ cells in this model depended on NKG2D binding and perforin production. Others reported that activated NK cells eliminate $\mathrm{CD} 4^{+} \mathrm{T}$ cells in a perforin-dependent manner, which might indirectly affect $\mathrm{CD}^{+} \mathrm{T}$ cell function and exhaustion during LCMV infection [1]. We did not observe an effect of NK cell depletion on $\mathrm{CD} 4^{+} \mathrm{T}$ cell responses suggesting a direct suppressive effect of NK cells on $\mathrm{CD}^{+}{ }^{+} \mathrm{T}$ cells in our model. Others demonstrated that NK cell depletion during high-dose influenza infection improved the survival rate of infected mice which was not seen in medium- or low-dose influenza infections $[3,13,14]$. The data indicate that viral loads might predict the effector functions of NK cells. Moreover, during herpes virus infection, a regulatory role of NK cells was described. It was shown that a strong NK cell response can limit $\mathrm{T}$ cell responses in MCMV infection $[15,16]$. Altogether, it seems that the balance of NK and $\mathrm{T}$ cell responses seems to be critical for viral immunity and the impact of NK cells depends on the type and dose of virus as well as the phase of virus infection. Thus, it is very important to further investigate the factors that influence NK cell regulatory functions.

\section{Additional file}

Additional file 1: Material and Method.

\section{Competing interests}

The authors have declared no competing interests.

\section{Authors' contributions}

EL performed the experiments, analyzed the data and participated in the statistical analysis. SF carried out the experiments. UD conceived and designed the experiments and wrote the paper. KG performed the experiments, analyzed the data, participated in the statistical analysis and wrote the paper. All authors read and approved the final manuscript.

\section{Acknowledgements}

This work was supported by a grant from the University Hospital Essen (IFORES).

Received: 13 May 2013 Accepted: 29 October 2013

Published: 1 November 2013

\section{References}

1. Waggoner SN, Cornberg M, Selin LK, Welsh RM: Natural killer cells act as rheostats modulating antiviral T cells. Nature 2012, 481(7381):394-398.

2. Lang PA, Lang KS, Xu HC, Grusdat M, Parish IA, Recher M, Elford AR, Dhanji $S$, Shaabani N, Tran CW, et al: Natural killer cell activation enhances immune pathology and promotes chronic infection by limiting CD8+ T cellimmunity. Proc Natl Acad Sci USA 2012, 109(4):1210-1215.

3. Zhou G, Juang SW, Kane KP: NK cells exacerbate the pathology of influenza virus infection in mice. Eur J limmunol 2013, 43(4):929-938.

4. Soderquest K, Walzer T, Zafirova B, Klavinskis LS, Polic B, Vivier E, Lord GM, Martin-Fontecha A: Cutting edge: CD8+ T cell priming in the absence of NK cells leads to enhanced memory responses. J limmunol 2011, 186(6):3304-3308.

5. Matusali G, Tchidjou HK, Pontrelli G, Bernardi S, D’Ettorre G, Vullo V, Buonomini AR, Andreoni M, Santoni A, Cerboni C, et al: Soluble ligands for the NKG2D receptor are released during HIV-1 infection and impair NKG2D expression and cytotoxicity of NK cells. FASEB J 2013, 27(6):2440-2450.

6. Alter G, Heckerman D, Schneidewind A, Fadda L, Kadie CM, Carlson JM, Oniangue-Ndza C, Martin M, Li B, Khakoo SI, et al: HIV-1 adaptation to NK-cell-mediated immune pressure. Nature 2011, 476(7358):96-100.

7. Ogawa T, Tsuji-Kawahara S, Yuasa T, Kinoshita S, Chikaishi T, Takamura S, Matsumura H, Seya T, Saga T, Miyazawa M: Natural killer cells recognize 
friend retrovirus-infected erythroid progenitor cells through NKG2D-RAE-1 interactions In Vivo. J Virol 2011, 85(11):5423-5435.

8. Gibbert K, Joedicke JJ, Meryk A, Trilling M, Francois S, Duppach J, Kraft A, Lang KS, Dittmer U: Interferon-alpha subtype 11 activates NK cells and enables control of retroviral infection. PLoS Pathog 2012, 8(8):e1002868.

9. Zelinskyy G, Dietze KK, Husecken YP, Schimmer S, Nair S, Werner T, Gibbert K, Kershaw O, Gruber AD, Sparwasser T, et al: The regulatory T cell response during acute retroviral infection is locally defined and controls the magnitude and duration of the virus-specific cytotoxic T cell response. Blood 2009, 114(15):3199-3207.

10. Manzke N, Akhmetzyanova I, Hasenkrug KJ, Trilling M, Zelinskyy G, Dittmer $\mathrm{U}: \mathrm{CD} 4+\mathrm{T}$ cells develop antiretroviral cytotoxic activity in the absence of regulatory T cells and CD8+ T cells. J Virol 2013, 87(11):6306-6313.

11. Shimizu T, Uenishi H, Teramura Y, Iwashiro M, Kuribayashi K, Tamamura H, Fujii N, Yamagishi H: Fine structure of a virus-encoded helper T cellepitope expressed on FBL-3 tumor cells. J Virol 1994, 68(12):7704-7708.

12. Diana J, Lehuen A: NKT cells: friend or foe during viral infections? Eur Immunol 2009, 39(12):3283-3291.

13. Gazit R, Gruda R, Elboim M, Arnon TI, Katz G, Achdout H, Hanna J, Qimron U, Landau G, Greenbaum E, et al: Lethal influenza infection in the absence of the natural killer cell receptor gene Ncr1. Nat Immuno/ 2006, 7(5):517-523.

14. Stein-Streilein J, Guffee J: In vivo treatment of mice and hamsters with antibodies to asialo GM1 increases morbidity and mortality to pulmonary influenza infection. J Immunol 1986, 136(4):1435-1441.

15. Andrews DM, Estcourt MJ, Andoniou CE, Wikstrom ME, Khong A, Voigt $V_{\text {, }}$ Fleming P, Tabarias H, Hill GR, van der Most RG, et al: Innate immunity defines the capacity of antiviral T cells to limit persistent infection. J Exp Med 2010, 207(6):1333-1343.

16. Lee SH, Kim KS, Fodil-Cornu N, Vidal SM, Biron CA: Activating receptors promote NK cell expansion for maintenance, IL-10 production, and CD8 T cell regulation during viral infection. J Exp Med 2009, 206(10):2235-2251.

doi:10.1186/1742-4690-10-127

Cite this article as: Littwitz et al:: Distinct roles of NK cells in viral immunity during different phases of acute Friend retrovirus infection. Retrovirology 2013 10:127.

\section{Submit your next manuscript to BioMed Central and take full advantage of:}

- Convenient online submission

- Thorough peer review

- No space constraints or color figure charges

- Immediate publication on acceptance

- Inclusion in PubMed, CAS, Scopus and Google Scholar

- Research which is freely available for redistribution 